\title{
Working to Improve Classroom Climate Using a Ten Point Scale and Focusing on the Development of the Classroom Management Skills of Individual Teachers
}

\author{
Terry Haydn \\ School of Education, University of East Anglia, Norwich, UK \\ Email: t.haydn@uea.ac.uk
}

Received 22 September 2015; accepted 22 December 2015; published 25 December 2015

Copyright (C) 2015 by author and Scientific Research Publishing Inc.

This work is licensed under the Creative Commons Attribution International License (CC BY). http://creativecommons.org/licenses/by/4.0/

C) (i) Open Access

\section{Abstract}

The working atmosphere in the classroom is an important variable in the process of education, with several studies suggesting that classroom climate has a significant impact on student attainment. Recent international studies have suggested that deficits in classroom climate are prevalent in many countries, pointing out that these deficits are more serious and prevalent in some systems compared to others. Attention has also been drawn to the phenomenon of "in-school variation", with levels of classroom control varying not just between schools, but also, within them. The paper describes the use of a 10 point scale for conceptualising the working atmosphere in the classroom as a continuum between a climate which is ideally conducive to learning (level 10), to a level where learning is severely constrained by the poor behaviour of some pupils (level 1). The scale encourages teachers, student teachers, school managers and school governors to reflect on the factors influencing the working atmosphere in the classroom. In England, there has been a tendency to see school leaders as the key to levels of classroom control (Ofsted, 2014; Wilshaw, 2014). However, this does not explain the phenomenon of "in-school variation" in classroom climate. The research outlined in this paper supports Elliott's view (Elliott, 2009) that the classroom management skills of individual teachers are one of the key determinants of classroom climate and good pupil behaviour, and therefore more time and effort need to go into developing this dimension of teacher authority. Working with teachers and student teachers, using the 10 point scale to develop their understanding of factors influencing classroom climate offers one way of developing teachers' skills in this area. Given that deficits in classroom climate and pupil behaviour are not limited to the UK, the scale may be of use and interest to those involved in teaching and teacher education in other countries.

\section{Keywords}

Behavior, Classroom Climate, Discipline in Schools, Action Research, Professional Voice, Teacher 


\section{Introduction}

In the popular TV series The Wire, Series 4, Episode 4 depicts a scene where a group of truants have been rounded up by social services personnel and have been persuaded to "give school another chance". The students duly go back into school, and into the classroom, but within the course of the first lesson, the poor behaviour of other students in the class, and the inability of the teacher to sustain a working atmosphere in which learning is practicable, leads the pupils to conclude that school is a waste of their time, and they walk out of the class, and away from the school, to resume their life outside of the school system.

Although the picture painted in this scene is fairly extreme, in terms of the scale of disruptive behaviour involved, there are few educational systems which can claim that there are no schools where deficits in classroom climate limit the amount of learning which takes place in classrooms, or situations where some students sometimes impede the learning of others.

Moreover, recent PISA and TIMMS reports (see, for example, OECD, 2009; TIMMS, 2011), and other comparative studies of educational attainment (Elliott \& Phuong Mai, 2008; Miller et al., 2009) have suggested that deficits in classroom climate are prevalent in many countries, pointing out that these deficits are more serious and prevalent in some systems compared to others. Hallam (2011) points out that in recent international comparisons, such as the PISA 2009 figures (Bradshaw et al., 2010), the US and UK emerge well down the "league table" of orderly and well-disciplined classrooms.

Attention has also been drawn to the phenomenon of "in-school variation", with levels of classroom control varying not just between schools, but also within them (Stewart, 2011). The study reported in this paper finds that the "level" of control prevailing with the same group of pupils may vary between "level 1" and "level 10" (see Appendix 1), depending on which teacher is taking the class. This raises the important question of why pupils behave better for some teachers than others, even within the same school. The use of the 10 point scale is designed to get teachers and student teachers to reflect on this question.

Classroom climate also has an important influence on educational systems and outcomes in terms of its influence on teacher recruitment and retention. In the UK, over $40 \%$ of teachers leave the profession within 5 years of qualification, and difficulties in coping with poor pupil behaviour emerge as one of the most commonly cited reasons for leaving teaching in the UK (Cockburn and Haydn, 2004, Barmby, 2006), with teacher retention also proving to be a problem in many other OECD countries (Guarino et al., 2006; Menter et al., 2002). In addition to learning deficits caused by poor classroom climate, Ronfeldt et al. (2013) have pointed out that high levels of teacher attrition and turnover also have a damaging effect on pupil attainment.

The scale attempts to provide a nuanced calibration of the extent to which the teacher is in control of the classroom, and able to create and sustain a working atmosphere that optimises pupil learning. The outcomes of the research suggest that there are worrying deficits in classroom climate in many English schools. However, such deficits are not limited to schools in England. Research suggests that poor pupil behaviour is a problem worldwide (see, for example, Elliott \& Phuong-Mai, 2008; Saito et al., 2015). The research may well therefore be of interest to educational jurisdictions beyond England.

\section{Method}

In terms of theoretical perspectives and frameworks, the research falls within the paradigm of "professional voice", where there is an attempt to gain greater insight into educational situations, issues and problems by eliciting the views of experienced professionals (Goodson, 1996; Sikes, 2006). There are also elements of an Action Research approach (Elliott, 1992), in that participants were asked to reflect on their ideas about the factors and variables influencing classroom climate, in order to develop "situational understanding", and (hopefully) improve the quality of their decision making in order to improve practice in social situations.

The main research instrument used in the research was a 10 level scale which has been widely used in teacher education in the UK (Haydn, 2012). The scale attempts to describe the continuum between classrooms where the working atmosphere is ideally conducive to learning, and classrooms where learning is severely limited by pupil 
disruption.

The idea in phrasing the level descriptors was to attempt to evince a chord of recognition in practising teachers and pre-service teachers, and to be sufficiently transparent and accessible as to be meaningful to others involved in the educational process-teachers, parents, governors and policy makers. The scale was originally used in work with pre-service teachers, based on the idea that it would be helpful for them to have some ideas about where they stood in the classroom climate continuum, to think about levels to aspire to, about what factors influenced the working atmosphere in the classroom, and why there were differences both between and within schools. Respondents were given a copy of the scale prior to a semi-structured interview and asked to talk about their experiences of teaching and observing other teachers' lessons in relation to the scale. Questions included:

- What sort of levels have you encountered in your teaching?

- What sort of levels have you observed in your experiences in schools?

- What factors influence levels of control and variations in classroom climate?

- Why do some teachers appear to be able to get to higher levels on the scale than others in their lessons?

- What factors other than the experience and classroom teaching skills of the individual teacher influence the working atmosphere in classrooms?

Respondents were also asked to consider what influence the working atmosphere had on their lesson planning and teaching, in terms of learning objectives and pedagogy. Implicit in the level descriptors is the suggestion that below a certain point on the scale, the atmosphere in the classroom will influence not just the outcomes of the learning process, but the inputs as well, in that below certain levels on the scale, planning may be directed to at least some extent towards the objective of control rather than learning.

The scale also aimed to get respondents to think about the extent to which there is a "right to learn" for pupils, free from disruption by other pupils, and to encourage them to reflect on the factors influencing classroom climate, the influence of classroom climate on teaching and learning, and the equal opportunities issues surrounding the tension between the ideals of educational inclusion and situations where some pupils are impeding the learning of others.

Between 2007 and 2011, interviews were conducted with 140 teachers. In terms of factors influencing sampling, the most influential factor influencing the choice of participants was that the respondents were heads and teachers known to the researcher.

Whilst acknowledging the threats to reliability of "insider research" (Elliott, 1988) and the limitations of face validity (Moores et al., 2012), a working hypothesis, albeit a tentative one, was that people with whom one had a reasonably close and (hopefully) positive working relationship might be more likely to feel that they could/ should be open and 'honest' in their responses, in what is acknowledged to be a sensitive facet of teachers' professional lives (Bennett, 2010; Haydn, 2012; Rogers, 2011). As Charles Taylor, behaviour advisor to Michael Gove, the Secretary of State for Education has pointed out.

Schools are very reluctant to admit they have an issue with behaviour... It's also interesting because it shows an emotional component to behaviour. There's an element of threat around behaviour that there almost isn't around any other issue in school. Deep down, behaviour is our biggest fear... There is a pride about it... in the same way that schools don't like to admit that they have a problem with behaviour, nor do teachers (Taylor, 2011: p. 20).

(The idea of "trust" sampling, in areas where there may be external pressures on respondents' testimony is explined in more depth in Haydn (2014)). Other factors influencing the choice of participants included the desire to obtain testimony from teachers with varying degrees of experience and seniority. The sample included 14 head teachers, 20 newly qualified teachers (in their first year of teaching), 12 assistant principals, 60 teachers who were either heads of department and/or mentors responsible for the supervision of student teachers, with the remainder of the sample comprising of teachers who were beyond their first year of teaching but who were not part of senior or middle management teams.

A third factor influencing sampling was the desire to gain insights into classroom climate from a representative sample of English schools. Over 85\% of the interviews were conducted with teachers working in the East of England because of the author's experience of working with them. The other 15\% came from schools in London and the North of England, for the same reason. The schools were not selected on the grounds of being particularly challenging or difficult. Nine of the respondents worked or had worked in schools "in special measures", but many worked in schools which were oversubscribed, and had received various awards and distinctions. Seven of the respondents worked or had worked in the independent sector at some point. Overall, the teachers 
came from schools which were broadly representative of English schools. The gender balance of the sample also closely represented the proportion of male and female teachers working in the English secondary school system.

Coding of the interview transcripts was done inductively, and responses were divided into testimony which indicated that classroom climate was not a major problem (defined as "nearly all lessons functioning at levels 9 or 10 on the scale"), testimony which stated that behaviour was an issue, and teachers had to at least some extent plan lessons around control issues (the middle order levels on the scale), and testimony that suggested substantial and regular deficits in classroom climate, with levels falling into the bottom half of the 10 point scale.

\section{Results}

\section{- Evidence of teacher reflection on the classroom climate continuum}

There were a number of responses which indicated that using the scale had elicited reflection on the working atmosphere in the classroom, from teachers with very differing degrees of classroom experience. Three examples are given below:

"It is helpful to think that there are lower levels on the scale than the ones I am working at. I have become aware of the massive differences even within this school... the time of day, the weather, the area of the school... some departments have it more sewn up than others" (Experienced Teacher).

"I have worked with some teachers who seem perfectly happy with levels around 7 and 8; they don't seem that bothered about going the extra mile to get the kids really sorted out so that they can just go in there and relax" (Head of Year).

"There's a stage at which, if you are at level 9 or 10 for a few lessons in a row... where they get used to it and it becomes "the norm". They expect the lesson to be OK. There's a lot of behaviourism in it. They can be conditioned to behave... Not in a fascist, control freak way but just getting them used to things... rituals and routines, being able to have a bit of a laugh and relax at some points in the lesson" (Experienced Teacher).

"I worried that talking about, or even acknowledging the lower levels on the scale might increase the trainees' anxieties about class management. It's an area that a lot of them are wound up about when they are in the early stages of first placement. But it led to some light hearted discussion of levels which they had encountered when they were pupils and given that none of them were at level 1 with all their classes, they could see that things could be worse..." (Assistant Head).

- Developing teachers' and pre-service teachers' understanding of the importance of classroom climate

Where student teachers or teachers had experienced "level 10" lessons, which are characterised on the scale by the teacher being in relaxed control of the class, and all pupils being keen to learn and work together with the teacher towards the learning objectives for the lesson (see Appendix 1), several interviewees remarked on the impact it had on student learning, the quality of their teaching, and perhaps most strikingly, the effect it had in terms of job satisfaction, even in comparison to lessons where behaviour was not a major problem. Four examples of respondent testimony are given, as being representative of feedback on what it was like, teaching "at level 10":

"I cannot stress how wonderful it is to teach a well behaved class. It actually enables you to lower your guard and completely relax. Even though I was teaching them about a religious pilgrimage, I really enjoyed the lesson and the children did too... I could tell" (Student Teacher).

"In a funny sort of way, it puts a bit of pressure on you when you've got a great class which you get on really well with... you keep thinking what you are going to do to give them a great lesson... to keep it up... it keeps you on your toes. But the lessons are great. You come out feeling great. You know that you have their respect, they rate you, they think you are a good teacher" (Newly Qualified Teacher).

"Your teaching actually gets better when you are at levels 9 and 10... your exposition is more fluent, you can think of things off the top of your head... you seem to be able to think of lots of good ideas because you' re not thinking at the back of your mind about control and surveillance issues. You get a buzz out of it and you can let your hair down more, take a few more risks" (Experienced Teacher).

"I've got a year 10 GCSE class (15 year olds, examination group) who are fantastic, a real pleasure to teach. I can often get level 8 and sometimes 9 and 10... that feeling that you can do anything.... They respond brilliantly... there's a good positive climate in the classroom. I think we all really enjoy the lessons" (Advanced Skills Teacher, Working in a Challenging School).

"In terms of how much you enjoy your teaching, there's a massive difference between operating at levels 7 
and $8 . .$. which are OK... no big hassle... and level 10, when it's just a fantastic job, pure pleasure... you can get a real buzz out of the interaction with pupils. It's like the adverts for teaching on the TV but in real life" (Newly Qualified Teacher).

Conversely, where teachers and student teachers were struggling to sustain a reasonable working atmosphere in the classroom, and encountering the lower levels on the scale (even in terms of the intermediate levels on the scale), there was an acknowledgement that this had a negative effect on how much learning would be achieved. Even experienced teachers acknowledged that they would adjust the format and aims of the lesson to try and minimise disruption, by "keeping pupils busy", "keeping their heads down", "Give them lots of written tasks", and eschewing activities such as group and discussion work. Where classroom climate sank to some of the lower levels on the scale (usually around level 4 and below) some teachers suggested that the whole process became more or less, a waste of time, with it being difficult to attain any worthwhile educational objectives in the lesson. It should be acknowledged here that not all schools suffered from the lower levels on the scale: in some schools, teachers felt that levels did not generally go below level 6 , but there appeared to be very few schools where the working atmosphere was consistently at levels 9 and 10 (Haydn, 2012).

Another implication of classroom climate falling to below (around) level 7 on the scale was the transformation of teachers' feelings about "doing the job" and "being a teacher". As well as making it difficult to enjoy teaching, it evinced feelings of guilt at "letting some pupils down", and "feeling a failure", as the following, not untypical extract demonstrates:

"You are aware that even in your most difficult classes, there are some kids who just quietly get on with it, who would like to learn but who are quietly fed up... or quietly resigned about the fact that the whole lesson will be pretty much a shambles because I haven't got the power to stop some of the pupils destroying the lesson. It's a horrible feeling, because obviously you blame yourself and think what more you could do... and then you walk past the other classrooms and see it happening to teachers who've been at the school for years" (Student Teacher).

\section{- Developing an understanding the importance of school context}

Where teachers had worked in more than one school, and where student teachers had worked in schools with differing levels of challenge in terms of student behaviour, there was an acknowledgement of the importance of "school context" in considering and acting on issues of pupil behaviour and classroom climate. This was important not just in terms of realising that what worked in one school may not work in another, but also in terms of realising that in terms of the challenges involved in managing pupil behaviour, in the UK system as elsewhere, it is not "a level playing field" (Elliott \& Phuong-Mai, 2008), and that some teachers have to deal with a far higher proportion of difficult pupils than others:

"It's difficult to do this job without thinking how unfair the system is. I've worked in several schools and it's so obviously not a fair contest. I used to work in an inner city school with a lot of difficult kids. The staff were great, a lot of them were fantastic teachers. My exam results there weren't great... now I work at a much easier school and I get a lot of praise for my exam results. I'm the same teacher" (Experienced Head of Department).

"I had a very successful first placement and was told by both the teachers I worked with and my university tutor that class management appeared to be a particular strength. I did feel confident and was able to get a good working atmosphere with all my classes. Then I went to a similar school down the road and just could not get the control I was used to... it was traumatic having been able to get control and then feeling impotent... helpless. The staff was great and very supportive but I spent a lot of time in tears in the staffroom and nearly packed it in" (Head of Department).

Another experienced teacher who had worked in two state schools and then moved to a private "prep" school talked of "educational overachievement" in the latter, raising important points about the extent to which there is "a right to learn" for all pupils in state schools under the current system:

"The kids here aren't that different from the kids at $X$ and $Y$ in terms of how bright they are. There's an amazing amount of overachievement really. When you look at their IQ Test scores, they're nothing special and yet in terms of results, they do really well. Nothing is allowed to get in the way of their learning, and there's none of the settling them down, getting them quiet stuff that wastes so much time. We have some kids here who are bone idle, who don't want to do well and have to be forced... but they are never allowed to spoil the learning of others" (Experienced Teacher).

- Developing an understanding that "teachers make a difference" to classroom climate

In spite of the acknowledgement that school context and the socio-economic background of a school's intake 
often has at least some impact on the levels of pupil behaviour and classroom climate prevailing in schools, testimony from teachers and student teachers overwhelmingly suggested that they believed that as Reynolds (1999) has argued, the teaching skills of the individual teacher are generally the most important determinant of classroom climate, given the extent and prevalence of 'in-school variation'. In the words of Reynolds:

In statistical analyses it is clear that the teacher "level" explains three to four times more in terms of pupil results than the school "level". Second, there is evidence of substantial variability in quality within our schools, in terms of departmental performance and in teachers' effectiveness. Indeed, the range of effectiveness within schools dwarfs the variation between them (Reynolds, 1999: p. 13).

Teacher and student teacher reflection on, and discussion of why some teachers operated at very different levels on the 10 point scale, even within the same school, teaching the same pupils, made it clear that in spite of variations in the degree of challenge which schools posed, teachers were not simply helpless victims of "the system", and could make a big difference to lesson climate and pupil behaviour. In the words of two student teachers:

'You couldn't do a placement at X school without realising what a fantastic difference the individual teacher makes. Groups that I had regarded as unteachable would behave like little angels, not just under control but relaxed, pleasant, helpful. They would just go quiet when he gave some small signal that he wanted to talk. At one level it was depressing because it made me realise how crap I was, but in another way it was inspiring... it made you realise what a fantastic difference teachers can make".

"You can't do a school placement without realising that the bottom line, in terms of the deal that the pupil gets, is which teacher they have".

A Teaching Assistant (TA) pointed out that they are in a good position to consider "teacher effect", given that by the nature of their job, they have to work with a wide range of teachers:

"As a TA you sometimes follow a group or a particular pupil around for the whole day or even for several lessons over a period of weeks. You would see the same group at level 10 with some teachers and down to level 2 or 3 with others. It made you realise what a massive difference the individual teacher makes. It made you really appreciate just how good some of them are, how wide the range of skills are that enable you to cope in difficult circumstances. You can also learn from bad practice... you can see what it is that some teachers do that puts their backs up... that sets them off, provokes them almost".

- Developing insight into the qualities and attributes of teachers who are effective in managing pupil behaviour

Headteachers and principals who were interviewed were keen to stress that levels of competence in this area were not simply a function of how many years of experience teachers had, or "innate"/"genetic" talent or capability:

"Like most heads, I have some teachers who are exceptionally accomplished at working with difficult and troubled pupils, they are incredibly resourceful, persevering... and clever. Some students and NQTs learn from them, others don't pick things up".

"I've got teachers here who have worked in this school for years who are still at level 3 with some of their classes, and I've got NQTs who are already very assured in dealing with pupil behaviour, who have virtually no problems with their classes after the first term. Some teachers are much better than others at this... it's not just a question of serving your time".

In terms of testimony from teachers, the qualities and attributes most commonly associated with teachers who were accomplished in their management of student behaviour were application, the ability to learn from the good practice of others, being able to plan high-quality learning experiences for pupils, high-level skills of interaction with students, and an understanding that there were different ways of being 'good at behaviour'-a range of 'styles' of managing pupil behaviour was possible (further development of these points can be found in Haydn (2012).

\section{Discussion: What Use Is the 10 Point Scale?}

It should be stressed that the aim of the scale is to facilitate reflection and dialogue on classroom climate and pupil behaviour. It was not designed to assess the classroom competence of teachers, and if used in the wrong way (for instance, to evaluate teacher performance) it may well do more harm than good. Although the teacher is an important element in influencing the working atmosphere in the classroom, deficits in classroom climate 
can be caused by a particularly difficult group of students, an inappropriate curriculum, inadequate resources, lack of effective support and sanctions or parental support, or any number of factors beyond the control of the classroom teacher. In initial experiments with the scale, student teachers were simply given the 10 point scale and asked to think about the levels on the scale in the context of both the students' own lessons, and their observation of colleagues' lessons. In the right atmosphere, in addition to encouraging reflection on this important aspect of teaching, it can lead to discussion and dialogue, the sharing of good practice, the discussion of refinements to school policy and practice, and collaborative 'lesson study' approaches to honing and refining teacher expertise (Elliott, 2012). The scale gives student teachers an indication of "levels to aspire to", and some indication of where they stand on the continuum between a classroom climate that is ideally conducive to learning, and one where the learning environment is profoundly unsatisfactory, as the following extracts suggest:

"I have worked with some teachers who seem perfectly happy with levels around 7 and 8; they don't seem that bothered about going the extra mile to get the kids really sorted out so that they can just go in there and relax" (Head of Year).

"It is possible that there are staff here who have neither experienced or seen a level 10 lesson... who think that the norm... or an inevitable fact of life in teaching... at least in this school... is that pupils talk while they are talking... that they move around and ignore the formal structure of the lesson at some points" (Assistant Head).

The scale can also be used to generate professional discussion and debate about "thresholds" for pupil inclusion within classrooms. At what point does a pupil forfeit the right to stay in a classroom? Are there any principles or criteria which might be agreed amongst those involved?

Discussion around the issues involved in the use of the scale may also help to improve the quality of dialogue surrounding issues of student behaviour in schools. In the popular media in the UK, this question is often simplified to thinking that lessons are simply under the control of the teacher or not, whereas in many educational jurisdictions, there are subtle and graded levels of control in classrooms, which can have a profound effect on learning outcomes (Bradshaw et al., 2010; OECD, 2010). Similarly, deficits in classroom climate are often attributed entirely to bad teaching or poor schools (Haydn, 2012). Level 10' is not a natural state of affairs, and in most countries, it takes considerable skill on the part of the teacher to get a climate which is perfect for learning, with all pupils keen to learn, with all their teaching groups. Elliott (2009) makes the point that becoming good at managing pupil behaviour is not just a simple matter of a few obvious and straightforward teaching strategies (for instance, “Just be consistent”, or "Don't smile before Christmas"). Securing a classroom climate where the teacher is in absolutely relaxed and assured control of the lesson, able to undertake any form of activity, and where all pupils are keen to learn and cooperate in this enterprise requires the development of complex and sophisticated skills on the part of the teacher. The scale aims to engage teachers and student teachers in constructive dialogue about the nature of these skills.

In England, there has been a tendency to see school leaders as the key to levels of classroom climate, and school systems as the most influential determinant of levels of classroom control (Ofsted, 2014; Wilshaw, 2014). However, these factors do not explain the phenomenon of "in-school variation" in classroom climate-in England, as in many other countries, differences within schools have been found to be more significant than in differences between schools in terms of the levels of behaviour that prevail in classrooms (see, for example, Elliott, 2009; Haydn, 2014; Wubbels, 2011, 2013).

The research outlined in this paper supports Elliott's view (Elliott, 2009) that the classroom management skills of individual teachers are one of the key determinants of classroom climate and good pupil behaviour, and therefore more time and effort need to go into developing this dimension of teacher authority. Working with teachers and student teachers, using the 10 point scale to develop their understanding of factors influencing classroom climate offers one way of developing teachers' skills in this area.

\section{Conclusion}

The research was conducted in schools in England, but the problem of learning deficits due to poor pupil behaviour was a global one, not a national one (Elliott \& Phuong-Mai, 2008; Saito et al., 2015). The paper argues that the use of the scale can provide useful insights into the extent to which there is a "right to learn" for pupils who wish to do so. It also raises important questions about what teachers and schools may do to protect "the right to learn", and to improve the working atmosphere in the classroom, so that there is a classroom climate 
which is ideally conducive to learning taking place, free from the damage to learning that can be caused by difficult and disruptive pupils.

The hope is that the scale can be useful in making teachers (and students, school governors, policymakers and parents) aware of the range of differences that can occur in terms of classroom climate. This awareness should then lead to discussions to explore the reasons for these differences, and to concerted attempts to explore all possible means of ensuring that the highest levels on the scale prevail. This is what the overwhelming majority of students, parents and teachers want.

The scale and prevalence of deficits in classroom climate, and the negative impact of these deficits on pupil attainment should also be interest and concern to politicians and policymakers in the field of education.

The scale does not, in itself, provide answers to the problem of pupil disruption and poor classroom climate, but it can at least provide some insight into the prevalence and seriousness of these problems.

\section{References}

Barmby, P. (2006). Improving Teacher Recruitment and Retention: The Importance of Workload and Pupil Behaviour, Educational Research, 48, 247-265. http://dx.doi.org/10.1080/00131880600732314

Bennett, T. (2010). The behaviour guru. London: Continuum.

Bradshaw, J., Ager, R., Burge, B., \& Wheater, R. (2010). PISA 2009: Achievement of 15-Year-Olds in England. Slough: NFER.

Elliott, J. (1992). Action Research for Educational Change. Buckingham: Open University Press.

Elliott, J. (2012). Developing a Science of Teaching through Lesson Study. International Journal for Lesson and Learning Studies, 1, 108-125. http://dx.doi.org/10.1108/20468251211224163

Elliott, J. G. (2009). The Nature of Teacher Authority and Teacher Expertise. Support for Learning, 24, 197-203. http://dx.doi.org/10.1111/j.1467-9604.2009.01429.x

Elliott, J. G., \& Phuong-Mai, N. (2008). Western Influences on the East, Eastern Influences on the West: Lessons for the East and West. In J. Elliott, \& N. Phuong-Mai (Eds.), What the West Can Learn from the East: Asian Perspectives on the Psychology of Learning and Motivation (31-58). New York: Information Age Publishing.

Goodson, I. (1996). Teachers’ Professional Lives. London: Falmer Press.

Guarino, C., Santibañez, L., \& Daley, G. (2006) Teacher Recruitment and Retention: A Review of the Recent Empirical Literature. Review of Educational Research, 76, 173-208. http://dx.doi.org/10.3102/00346543076002173

Hallam, S. (2011). Quoted in “UK and Western Europe Joins US at Back of the Class on Behaviour”. Times Educational Supplement, 27 May 2011, 21.

Haydn, T. (2012). Managing Pupil Behaviour: Working to Improve Classroom Climate. London: Routledge

Haydn, T. (2014). To What Extent Is Behaviour a Problem in English Schools? Exploring the Scale and Prevalence of Deficits in Classroom Climate. Review of Education, 2, 31-64.

Menter, I., Hutchings, M., \& Ross, A. (Eds.) (2002). The Crisis in Teacher Supply: Research and Strategies for Retention. London: Trentham.

Miller, D., Sen, A., Malley, A., \& Burns, S. D. (2009). Comparative Indicators of Education in the United States and Other G-8 Countries: 2009 (NCES 2009-039). Washington DC: National Center for Education Statistics, Institute of Education Sciences, US Department of Education.

Moores, K., Jones, G., \& Radley, C. (2012). Development of an Instrument to Measure Face Validity, Feasibility and Utility of Patient Questionnaire Use during Health Care: The QQ-10. International Journal for Quality in Health Care, 24, 517524. http://dx.doi.org/10.1093/intqhc/mzs051

OECD (2009). Programme for International Student Assessment (PISA) Results: What Students Know and Can Do. Paris: OECD.

Ofsted (2014). Below the Radar: Low-Level Disruption in Classrooms. London: Ofsted. https://www.gov.uk/government/publications/below-the-radar-low-level-disruption-in-the-countrys-classrooms

Reynolds, D. (1999). It’s the Classroom, Stupid. The Observer, 28 May 1999, 13.

Rogers, B. (2011). Classroom Behaviour: A Practical Guide to Effective Teaching, Behaviour Management and Colleague Support. London: Paul Chapman.

Ronfeldt, M., Loeg, S., \& Wyckoff, J. (2013). How Teacher Turnover Harms Student Achievement. American Educational Research Journal, 50, 4-36. http://dx.doi.org/10.3102/0002831212463813 
Saito, E., Watanabe, M., Gillies, R., Someya, I., Nagashima, T, Sato, M., \& Murase, M. (2015). School Reform for Positive Behaviour Support through Collaborative Learning: Utilising Lesson Study for a Learning Community. Cambridge Journal of Education, 45, 489-518. http://dx.doi.org/10.1080/0305764X.2014.988684

Sikes, P. (2006). Working in a New University: In the Shadow of the Research Assessment Exercise. Studies in Higher Education, 31, 555-568. http://dx.doi.org/10.1080/03075070600922758

Taylor, C. (2011). Quoted in Vaughan, R. “There’s an Element of Threat... Deep Down, Behaviour Is Our Biggest Fear”. Times Educational Supplement, 22 July 2011, 20-21.

TIMMS (2011). Trends in International Maths and Science Study. Amsterdam: International Association for the Evaluation of Educational Achievement.

Wilshaw, M. (2014). Failure of Leadership in Tackling Poor Behaviour Costing Pupils. Department for Education Press Release, 25 September.

https://www.gov.uk/government/news/failure-of-leadership-in-tackling-poor-behaviour-costing-pupils

Wubbels, T. (2011). An International Perspective on Classroom Management: What Should Prospective Teachers Learn? Teaching Education, 22, 113-131. http://dx.doi.org/10.1080/10476210.2011.567838

Wubbels, T. (2013). Classroom Management around the World. Keynote Address to the Classroom Management Special Interest Group, AERA Conference, San Francisco, 27 April-1 May 2013. 


\section{Appendix 1: The Working Atmosphere in the Classroom: A Ten Level Scale}

The scale was devised to encourage student teachers to think about the degree to which teachers are in relaxed and assured control of their classrooms and can enjoy their teaching, and also, the extent to which there is a "right to learn" for pupils, free from the noise and disruption of others. It is not designed as an instrument to pass judgement on the class management skills of teachers (not least because there are so many other variables which influence the levels - most obviously, which school you are working in). Its purpose is to get student teachers (and teachers, departments and schools) to think about the factors influencing the working atmosphere in the classroom, the influence of the working atmosphere in classrooms on teaching and learning, and the equal opportunities issues surrounding the tension between inclusion, and situations where some pupils may be spoiling the learning of others.

Level 10 You feel completely relaxed and comfortable; able to undertake any form of lesson activity without concern. "Class control” not really an issue- - teacher and pupils working together, enjoying the experiences involved.

You feel completely in control of the class and can undertake any sort of classroom activity, but you need to exercise some

Level 9 control/authority at times to maintain a calm and purposeful working atmosphere. This can be done in a friendly and relaxed manner and is no more than a gentle reminder.

You can establish and maintain a relaxed and co-operative working atmosphere and undertake any form of classroom activity,

Level 8 but this requires a considerable amount of thought and effort on your part at times. Some forms of lesson activity may be less calm and under control than others.

You can undertake any form of lesson activity, but the class may well be rather "bubbly" and rowdy; there may be minor instances of a few pupils messing around on the fringes of the lesson but they desist when required to do so. No one goes out of their way to annoy you or challenges your authority.

You don't really look forward to teaching the class, it is often a major effort to establish and maintain a relaxed and calm atmosphere. Several pupils will not remain on task without persistent surveillance/exhortation/threats. At times you feel harassed,

Level 6 and at the end of the lesson you feel rather drained. There are times when you feel it is wisest not to attempt certain types of pupil activity, in order to try and keep things under control. It is sometimes difficult to get pupils to be quiet while you are talking, or stop them calling out, or talking to each other at will across the room but in spite of this, no one directly challenges your authority, and there is no refusal or major disruption.

There are times in the lesson when you would feel awkward or embarrassed if the head/a governor/an inspector came into the room, because your control of the class is limited. The atmosphere is at times rather chaotic, with several pupils manifestly not listening to your instructions. Some of the pupils are in effect challenging your authority by their dilatory or desultory compli-

Level 5 ance with your instructions and requests. Lesson format is constrained by these factors; there are some sorts of lesson you would not attempt because you know they would be rowdy and chaotic, but in the last resort, there is no open refusal, no major atrocities, just a lack of purposefulness and calm. Pupils who wanted to work could get on with it, albeit in a rather noisy atmosphere.

You have to accept that your control is limited. It takes time and effort to get the class to listen to your instructions. You try to get onto the worksheet/written part of the lesson fairly quickly in order to "get their heads down". Lesson preparation is influ-

Level 4 enced more by control and 'passing the time' factors than by educational ones. Pupils talk while you are talking, minor transgressions (no pen, no exercise book, distracting others by talking) go unpunished because too much is going on to pick everything up. You become reluctant to sort out the ringleaders as you feel this may well escalate problems. You try to "keep the lid on things" and concentrate on those pupils who are trying to get on with their work.

You dread the thought of the lesson. There will be major disruption; many pupils will pay little or no heed to your presence in

Level 3 the room. Even pupils who want to work will have difficulty doing so. Swearwords may go unchecked, pupils will walk round the room at will. You find yourself reluctant to deal with transgressions because you have lost confidence. When you write on the board, objects will be thrown around the room. You can't wait for the lesson to end and be out of the room.

The pupils largely determine what will go on in the lesson. You take materials into the lesson as a manner of form, but once distributed that will be ignored, drawn on or made into paper aeroplanes. When you write on the board, objects will be thrown at you rather than round the room. You go into the room hoping that they will be in a good mood and will leave you alone and just chat to each other.

Your entry into the classroom is greeted by jeers and abuse. There are so many transgressions of the rules and what constitutes

Level 1 reasonable behaviour that it is difficult to know where to start. You turn a blind eye to some atrocities because you feel that your intervention may well lead to confrontation, refusal or escalation of the problem. This is difficult because some pupils are deliberately committing atrocities under your notes, for amusement. You wish you had not gone into teaching. 